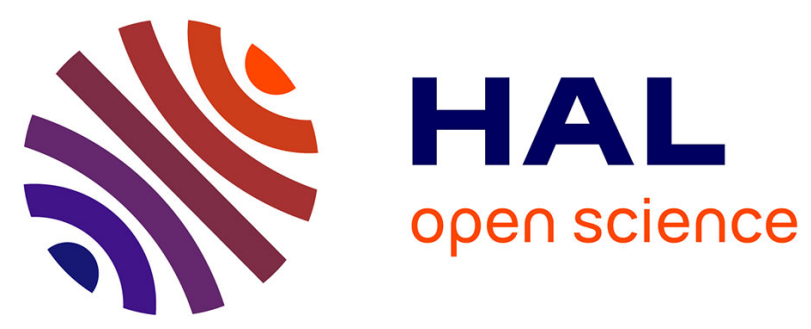

\title{
Constant versus variable-intensity during cycling: effects on subsequent running performance
}

\author{
Thierry Bernard, Fabrice Vercruyssen, Cyrille Mazure, Philippe Gorce, \\ Christophe Hausswirth, Jeanick Brisswalter
}

\section{- To cite this version:}

Thierry Bernard, Fabrice Vercruyssen, Cyrille Mazure, Philippe Gorce, Christophe Hausswirth, et al.. Constant versus variable-intensity during cycling: effects on subsequent running performance. European Journal of Applied Physiology, 2007, 99 (2), pp.103-111. 10.1007/s00421-006-0321-7 . hal01708106

\section{HAL Id: hal-01708106 https://hal-insep.archives-ouvertes.fr/hal-01708106}

Submitted on 13 Feb 2018

HAL is a multi-disciplinary open access archive for the deposit and dissemination of scientific research documents, whether they are published or not. The documents may come from teaching and research institutions in France or abroad, or from public or private research centers.
L'archive ouverte pluridisciplinaire HAL, est destinée au dépôt et à la diffusion de documents scientifiques de niveau recherche, publiés ou non, émanant des établissements d'enseignement et de recherche français ou étrangers, des laboratoires publics ou privés. 


\title{
Constant versus variable-intensity during cycling: effects on subsequent running performance
}

Thierry Bernard - Fabrice Vercruyssen - Cyrille Mazure - Philippe Gorce - Christophe Hausswirth - Jeanick Brisswalter

T. Bernard - F. Vercruyssen - C. Mazure - P. Gorce - J. Brisswalter Department of Sport Ergonomic and Performance, UFR STAPS, University of Sud Toulon-Var, BP 132, 83957 La Garde Cedex, France e-mail: thierry.bernard@univ-tIn.fr

C. Hausswirth Laboratory of Biomechanics and Physiology, French National Institute of Sport and Physical Education (INSEP), Avenue du Tremblay, 75012 Paris, France

\begin{abstract}
The aim of this study was to investigate the metabolic responses to variable versus constantintensity $(\mathrm{Cl})$ during 20-km cycling on subsequent 5-km running performance. Ten triathletes, not only completed one incremental cycling test to determine maximal oxygen uptake and maximal aerobic power (MAP), but also three various cycle-run (C-R) combinations conducted in outdoor conditions. During the $\mathrm{C}-\mathrm{R}$ sessions, subjects performed first a $20-\mathrm{km}$ cycletime trial with a freely chosen intensity ( $\mathrm{FCl}, \sim 80 \% \mathrm{MAP}$ ) followed by a $5-\mathrm{km}$ run performance. Subsequently, triathletes were required to perform in a random order, two $\mathrm{C}-\mathrm{R}$ sessions including either a $\mathrm{Cl}$, corresponding to the mean power of $\mathrm{FCl}$ ride, or a variable-intensity $(\mathrm{VI})$ during cycling with power changes ranging from 68 to $92 \%$ MAP, followed immediately by a $5-\mathrm{km}$ run. Metabolic responses and performances were measured during the $\mathrm{C}-\mathrm{R}$ sessions. Running performance was significantly improved after $\mathrm{Cl}$ ride (1118 $\pm 72 \mathrm{~s}$ ) compared to those after $\mathrm{FCl}$ ride (1134 \pm $64 \mathrm{~s})$ or VI ride $(1168 \pm 73 \mathrm{~s})$ despite similar metabolic responses and performances reported during the three cycling bouts. Moreover, metabolic variables were not significantly different between the run sessions in our triathletes. Given the lack of significant differences in metabolic responses between the $\mathrm{C}-\mathrm{R}$ sessions, the improvement in running time after $\mathrm{FCl}$ and $\mathrm{Cl}$ rides compared to VI ride suggests that other mechanisms, such as changes in neuromuscular activity of peripheral skeletal muscle or muscle fatigue, probably contribute to the influence of power output variation on subsequent running performance.
\end{abstract}

Keywords : Triathletes - Variable-intensity -Running performance - Metabolic responses

\section{Introduction}

The effects of metabolic responses and performance to constant versus variable-intensity bout on subsequent exercise have been examined especially during a cycle-cycle combination in trained cyclists (Palmer et al. 1997, 1999). For instance, Palmer et al. (1997) observed that following $150 \mathrm{~min}$ of steady-state riding, the subsequent $20-\mathrm{km}$ time trial performance was improved, as compared to $150 \mathrm{~min}$ of stochastic exercise (i.e. variable-intensity). Although the prior stochastic intensity did not affect systematically the subsequent cycling performance, changes in skeletal muscle carbohydrate metabolism or muscular recruitment during stochastic intensity suggest that the best pacing strategy would be to maintain a constant power output (PO) rather than a variable PO for as long as possible (Liedl et al. 1999; Palmer et al. 1999). However, it is important to note that this type of pacing strategy has been derived from cycling 
exercises conducted in laboratory settings or flat outdoor sessions, without any important changes in topography or wind conditions (Atkinson et al. 2003; Perrey et al. 2003; Swain 1997). In the context of triathlon field, many studies have investigated the effect of various cycling exercise on subsequent running performance (Bernard et al. 2003; Hausswirth et al. 1999, 2001; Vercruyssen et al. 2002, 2005). Experimental variables such as cadence (Bernard et al. 2003; Vercruyssen et al. 2002, 2005) and drafting during the cycling exercise (Hausswirth et al. 1999) have been shown to affect subsequent running responses. Hausswirth et al. (1999) indicated that the drafting component minimized the metabolic load (e.g. reduced oxygen uptake, ventilation and heart rate) during cycling and improved the subsequent $5-\mathrm{km}$ run bout in elite triathletes. More recently, a decreased metabolic load, consecutive to the selection of a low cadence $(<80 \mathrm{rpm})$ during the last $10 \mathrm{~min}$ of prolonged cycling, has been reported to improve markedly the subsequent running time to fatigue in trained triathletes (Vercruyssen et al. 2005). These metabolic responses and performances have been observed during various cycle-run (C$\mathrm{R})$ combinations conducted in both laboratory and field settings whereby subjects completed the cycling exercise at a constant PO.

Within this framework, a stability of the PO during a laboratory-based individual time-trial has been reported in trained triathletes (Perrey et al. 2003). The exercise intensity is also known to be relatively constant during flat cycling exercise of a triathlon race, especially in age-group athletes, who perform the cycle bout as an individual time trial. The inclusion of hills, technical bike courses or wind variations may change the PO profile and thereby, the physiological demands during triathlon races. Additionally, the constant PO profile is not observed within the groups of elite triathletes who cycle in a sheltered position inducing several changes of pace, intensity or stochastic shifts in the amplitude of the physiological responses throughout the duration of the cycle (Bentley et al. 2002). Regardless of the category of triathletes, it is likely, that a variation of PO profile, including more efforts close to the maximal aerobic power, may induce higher metabolic and/or neuromuscular fatigue during the cycling exercise (Sarre et al. 2005; Bentley et al. 2002; Lepers et al. 2002; StClair Gibson et al. 2001) resulting in a greater running performance decrement compared with a prior constant cycling bout.

Far less is known about the physiological responses to constant versus variable-intensity exercise during cycling and the consequences on subsequent running performance. To our knowledge, only Ramsay et al. (2001) have reported that varying intensity within the range of $20-40 \%$ of the average workrate during a 60 - min cycle time trial has no effect on subsequent $10-\mathrm{km}$ running compared to a constant cycling bout, in relatively untrained subjects. The previous studies leading to an improved running performance after a constant metabolic load during cycling (Hausswirth et al. 1999; Vercruyssen et al. 2002, 2005) suggest that the selection of a constant PO would be the best pacing strategy to induce a stability of metabolic responses during cycling and to reduce any decrements in running performance. To date, however, no data are available on the influence of various PO profiles during cycling on subsequent running performance in trained subjects and in outdoor conditions that simulate triathlon racing.

Accordingly, the objectives of the current investigation were to evaluate the metabolic responses of trained triathletes to field-based constant versus variable- intensity cycling and to examine the effects of these different exercise preloads on the subsequent 5- km running performance.

\section{Methods}

\section{Subjects}

Ten male triathletes, experienced in triathlon for more than 4 years, volunteered to participate in this experiment. All had regularly competed in triathlon racing at either sprint $(0.750-\mathrm{km} \mathrm{swim} / 20$ $\mathrm{km}$ cycle $/ 5-\mathrm{km}$ run) or short distances (1.5-km swim/40-km cycle/10-km run). Mean \pm SD training distances per week were $16.4 \pm 8.2 \mathrm{~km}$ in swimming, $222.7 \pm 80.2 \mathrm{~km}$ in cycling and $46.4 \pm 15.5$ 
$\mathrm{km}$ in running. Their mean $\pm \mathrm{SD}$ age, body mass and height were $25.2 \pm 6.8$ years, $71.8 \pm 8.4 \mathrm{~kg}$ and $181.3 \pm 6.7 \mathrm{~cm}$, respectively. Before beginning the tests, all subjects were informed about the risks involved and were required to give their written consent according to local ethical committee guidelines. During the study, all subjects were encouraged to undertake their normal training and diet, but not to train 2 days before each test. Each triathlete carried out an incremental cycling exercise in the laboratory and three $\mathrm{C}-\mathrm{R}$ sessions, in a field setting, over a 4-week period in April (temperature 15- 20_C, relative humidity 40-65\%, pressure 740- 760 $\mathrm{mmHg}$ and wind velocity $1.5-3.2 \mathrm{~m} \mathrm{~s}-1)$ at the same time of the day and separated by a rest period of at least $48 \mathrm{~h}$.

Maximal cycling test Subjects performed an incremental cycle exercise test to exhaustion, to determine maximal oxygen uptake (VO2max) and maximal aerobic power (MAP). This laboratory test was conducted on an electromagnetically braked ergometer SRM (Schoberer Rad Messtechnick, Fuchsend, Germany), the handlebars and racing seat of which were fully adjustable both vertically and horizontally. The ergometer was equipped with individual pedals, allowing the subjects to wear their own cycling shoes. The SRM Training System allowed athletes to maintain a constant PO, independent of cycling cadence. In addition, feedbacks concerning $\mathrm{PO}$ values were continuously available on a control screen.

After a 6-min warm-up at 100 Watt (W), the PO was increased by $30 \mathrm{~W}$ every 2 min until subjects could no longer maintain the required PO. The cycling cadence was freely chosen. During this test, oxygen uptake ( $\mathrm{V} \mathrm{O}$ 2) and expiratory flow (VE) were collected, and respiratory exchange ratio (RER) was calculated, using a telemetric system (Cosmed K4b2, Rome Italy) previously validated by McLaughlin et al. (2001). Heart rate (HR) values were monitored using a Polar unit (S710i, Polar Electro, Kempele, Finland). Expired gases and HR values were averaged every $10 \mathrm{~s}$. The four highest consecutive _V O2 values were summed to determine VO2max during the last minute $(61.9 \pm 4.1 \mathrm{ml} \mathrm{min}-1 \mathrm{~kg}-1)$. The MAP corresponded to the mean value during the last minute $(380 \pm 31 \mathrm{~W})$.

\section{Cycle-run combinations}

The same racing bike was used by all subjects and during all sessions. Bike tyre pressures were standardised at $800 \mathrm{kPa}$ for each session. The racing bike (KX Light, Look Cycle International, Nevers, France) was equipped with a "professional" SRM crankset system (Schoberer Rad Messtechnick, Fuchsend, Germany) previously validated in a protocol comparison using a motor driven friction brake (Jones and Passfield 1998). An almost perfect relationship ( $r 2=0.99-1.0$, $P<0.05)$ has been reported between the two systems. Moreover, the "professional" SRM was shown to have a very low $( \pm 1.8 \%$ or $\pm 2 \mathrm{~W}$ ) variability (Jones and Passfield 1998). This system was calibrated before each trial. The experimental racing bike had a saddle and handlebars, both adjustable for height (Ergostem, Look, Nevers, France) and triathletes had to use their own pedals.

All triathletes completed, in outdoor conditions, three C-R sessions, each composed of 20-km cycling (i.e. ten times a 2-km of straight line with traffic circles) on the racing bike and a subsequent $5-\mathrm{km}$ run bout. Before all sessions, each subject completed a $8-\mathrm{km}$ free cycling warm-up on the same flat road used for the C-R sessions. After $5 \mathrm{~min}$ of rest, subjects were equipped with the Cosmed K4b2 gas analyser to continuously collect respiratory gas measures. A Polar unit coupled with a receiver, connected to the SRM powermeter was used to store HR values. Triathletes were required to perform a first $\mathrm{C}-\mathrm{R}$ session during which the cycle bout corresponded to a time trial with a freely chosen intensity $(\mathrm{FCl})$. During the $\mathrm{FCl}$ ride, the PO, the cycling cadence, the speed and the HR values displayed on the SRM powermeter were masked. This $\mathrm{C}-\mathrm{R}$ session was systematically the first experimental condition performed by our subjects and allowed the identification of power strategies developed by triathletes on a flat road. The two other $\mathrm{C}-\mathrm{R}$ combinations were conducted in a random order during which the subjects had to 
maintain either a constant $\mathrm{PO}$ or intensity $(\mathrm{Cl})$ corresponding to the mean $\mathrm{PO}$ recorded during the overall $\mathrm{FCl}$ ride, or a variable-intensity (VI) during the cycling bouts before running (Fig. 1). Within this framework, the fixed $\mathrm{PO}$ during $\mathrm{Cl}$ and $\mathrm{VI}$ rides was determined by removing low $\mathrm{PO}$ and cadence values $(0-10 \mathrm{~W}$ or $0-10 \mathrm{rpm}$, i.e. free wheel situation) monitored during the two traffic circles. To maintain the mean PO, the subject referred to the SRM powermeter mounted on the handlebars. In the VI ride, the PO was imposed by various sections calculated from the mean $\mathrm{PO}$ recorded during the $\mathrm{FCl}$ ride. Thus, the subjects had to sustain a PO corresponding to a range of + and $-15 \%,+$ and $-5 \%$, - and $+10 \%$ of the mean $\mathrm{PO}$, respectively, to accomplish the first and the second 3-km sections (S1 and S2), the third and the fourth 4-km sections (S3 and S4), the fifth and the sixth 3-km sections (S5 and S6). During the last section of VI ride, triathletes were required to sustain a high $\mathrm{PO}$, to simulate the racing situation, where all triathletes attempt to enter within the transition area in the best position. The $\mathrm{VI}$ ride was designed to mimic the variable efforts over time during a previously investigated sprint distance triathlon during which we found that there was a high variation in $\mathrm{PO}$ during the cycle exercise in trained triathletes (unpublished data). Cycling cadence, PO and HR were monitored and stored every $5 \mathrm{~s}$ from the SRM powermeter and transmitted after testing bouts to a PC.

The PO variations were also calculated so that triathletes performed the similar amount of workrate whatever the wind direction. Wind speed was evaluated from an anemometer $(2.18 \pm$ $1.33 \mathrm{~m} \mathrm{~s}-1)$. After a transition time fixed at $40 \mathrm{~s}$, these three cycling paced rides were immediately followed by a $5-\mathrm{km}$ running performance which took place on a flat road with a traffic circle at every $500 \mathrm{~m}$. Additionally, the intermediate times were registered at every $500 \mathrm{~m}$ running section and subjects were not given any feedback other than the elapsed distance.

\section{Metabolic parameters measurements}

The VO2; VE and HR values were continuously monitored and averaged during the overall sections (S1-S6) of the cycling bouts. During the subsequent run, data were averaged over a 1 min period at the start, at every kilometer and during the end of the running bout. Four small blood samples ([La-]) of $5 \mu \mathrm{l}$ were collected from the earlobe using the Lactate Pro System (Arkray factory, Shigo, Japan) previously validated by Pyne et al. (2000) at the following intervals: before and after the warm-up, at the end of the cycling and running bouts. The duration between ending the cycling/running bouts and collecting of blood samples was approximately $10 \mathrm{~s}$.

\section{Ratings of perceived exertion (RPE)}

At the beginning of each test, subjects were provided with a typewritten set of standardised directions for the use of the ratings of perceived exertion (Borg 1970). Subjects were instructed to give an overall RPE immediately at the end of $\mathrm{FCl}, \mathrm{Cl}$, $\mathrm{VI}$ rides and the corresponding run bouts.

\section{Statistical analysis}

All data are expressed as mean values ( $\pm S D$ ). Normally Shapiro-Wilks' tests were conducted before statistical analysis and it was confirmed that all data were normally distributed. Subsequently, a two way ANOVA with repeated measures was performed to analyse the effects of cycling condition ( $\mathrm{FCl}, \mathrm{Cl}, \mathrm{VI}$ ) and time, during the $\mathrm{C}-\mathrm{R}$ combinations using VO2; VE; HR, [La-], cycling cadence, PO and RPE, as dependent variables. A Newman-Keuls post-hoc test was used to determine any differences between the $C-R$ sessions. Differences in running performance between the C-R combinations were analysed using a one-way analysis of variance. The 0.05 level of significance was used for all statistical procedures. 


\section{Results}

\section{Performances}

A significant decrease in running time was observed after $\mathrm{Cl}$ ride $(1118 \pm 72 \mathrm{~s})$ when compared to those after $\mathrm{FCl}(1134 \pm 64 \mathrm{~s},-1.4 \%)$ and $\mathrm{VI}(1168 \pm 73 \mathrm{~s},-4.4 \%)$ bouts $(\mathrm{P}<0.05)$. The running time was also significantly lower after the $\mathrm{FCl}$ ride compared to the after $\mathrm{VI}$ ride $(-2.9 \%$, $P<0.05)$. Furthermore, the running velocity was significantly higher during the first kilometre performed after $\mathrm{FCl}(4.57 \pm 0.26 \mathrm{~m} \mathrm{~s}-1)$ and $\mathrm{Cl}(4.57 \pm 0.31 \mathrm{~m} \mathrm{~s}-1)$ rides as compared to $\mathrm{VI}$ bout $(4.35 \pm 0.26 \mathrm{~m} \mathrm{~s}-1)$ (Fig. $2, \mathrm{P}<0.05)$.

Morever, subjects performed the $\mathrm{FCl}, \mathrm{Cl}$ and $\mathrm{VI}$ rides, respectively, at a mean $\mathrm{PO}$ and speed of $310 \pm 28$ and $37.8 \pm 1.9,306 \pm 36$ and $38.3 \pm 1.9,305 \pm 46 \mathrm{~W}$ and $37.5 \pm 3.0 \mathrm{~km} \mathrm{~h}-1$ during the $20-\mathrm{km}$ (Fig. 1). These mean PO values have been noted to be close to $80 \%$ of MAP. For the VI ride, $\mathrm{PO}$ values ranged from 68 to 92\% MAP (260-350 W). No significant differences in mean $\mathrm{PO}$ and speed were found between the three paced rides, indicating that our subjects fully respected the required $\mathrm{PO}$, whatever the condition. Mean cycling cadences were significantly lower at the end of the $\mathrm{Cl}$ ride, compared to the $\mathrm{FCl}$ ride $(-7.1 \%, \mathrm{P}<0.05)$.

\section{Metabolic responses}

Table 1 shows the changes in physiological parameters during the cycling bouts. A significant effect of exercise duration (between S1 and S6) was observed on VE and HR, for the three cycling bouts (Table 1, P $<0.05$ ). In contrast, no variation in VO2 was found with exercise duration. Moreover, no significant differences in mean VO2; VE; HR, [La-] and RPE values were observed between the three cycling bouts of $\mathrm{C}-\mathrm{R}$ sessions. [La-] values were $6.6 \pm 2.1,6.6 \pm$ 2.8 and $7.7 \pm 2.2 \mathrm{mmol} \mathrm{I}-1$, respectively at the end of $\mathrm{FCl}, \mathrm{Cl}$ and $\mathrm{VI}$ rides. RPE values were not significantly different at the end of cycling bouts, $16 \pm 2,16 \pm 1$ and $17 \pm 2$ respectively for $\mathrm{FCl}$, $\mathrm{Cl}$ and $\mathrm{VI}$ rides.

Table 2 shows the changes in physiological parameters during the $5-\mathrm{km}$ running bouts. A significant effect of exercise duration was observed on VO2; VE; and HR values $(P<0.05)$ between the first section and the other sections within the three run bouts whereas no significant variation in these metabolic parameters was found between the run sessions. Figure 2 indicates the VO2 responses and speed values throughout the three run performances. [La-] values were not significantly different between the running conditions $(7.9 \pm 1.3,8.1 \pm 1.9$ and $7.1 \pm 2.9 \mathrm{mmol}$ $\mathrm{I}-1$, respectively after $\mathrm{FCl}, \mathrm{Cl}$ and $\mathrm{VI}$. Similarly, no significant variation in RPE values was found between the run sessions (18 $\pm 1,18 \pm 1$ and $19 \pm 1$ respectively after $\mathrm{FCl}, \mathrm{Cl}$ and $\mathrm{VI})$.

\section{Discussion}

The main findings of the current investigation indicate that $20-\mathrm{km}$ of cycling at a constant-PO significantly improves subsequent $5-\mathrm{km}$ running performance, as compared to the condition where triathletes perform a prior cycling exercise at the $\mathrm{FCl}$ or $\mathrm{VI}$. Metabolic and muscular hypotheses are advanced in an attempt to explain the differences in performance reported during the various $\mathrm{C}-\mathrm{R}$ combinations for our group of well trained triathletes.

An interesting finding of the present work is related to the differences in running performance between the $\mathrm{C}-\mathrm{R}$ sessions, despite similar whole body responses (i.e. VO2; VE; HR and [La-]) and RPE values observed during the $\mathrm{Cl}$ ( $\sim 80 \%$ MAP) and VI (from 68 to $92 \%$ MAP, Fig. 1) cycling exercises. It has previously been proposed that the differences in running time may be related to changes in metabolic energy from aerobic and anaerobic sources (Brandon 1995). Thus, the analysis of variation in VO2 has often been used to assess changes in energy contribution from aerobic and anaerobic sources during isolated and combined exercises 
(Bernard et al. 2003; Bishop et al. 2002; Brandon 1995; Hausswirth et al. 2001; Vercruyssen et al. 2005). In the context of a C-R combination, Hausswith et al. (2001) have suggested that changes in aerobic contribution constitute potential limiting factors to running performance. These investigators reported a significantly higher fraction of VO2 max during an improved 5-km running performance, after cycling in a sheltered position by elite triathletes, suggesting that a higher aerobic contribution may be linked to the faster run time. Recently however, Vercruyssen et al. (2005) showed similar VO2 responses during exhaustive running sessions between different $\mathrm{C}-\mathrm{R}$ sessions, indicating that differences in run time to fatigue were not explained by changes in metabolic energy from the aerobic or anaerobic systems. In the present study, there were also no significant differences in the VO2 response during the three run conditions (Fig. 2). Thus, our findings, and those reported in a previous work (Vercruyssen et al. 2005), suggest that an altered VO2 response cannot explain the observed differences in running performance following different cycle strategies.

The differences in 5-km running performance may be explained by the PO selected during the entire cycling exercises. Compared to $\mathrm{Cl}$ and $\mathrm{FCl}$ rides, our triathletes sustained a very high $\mathrm{PO}$ $(\sim 92 \% \mathrm{MAP})$ during the last $3-\mathrm{km}$ of the $\mathrm{VI}$ ride and any changes in energy contribution from aerobic and anaerobic sources (e.g. VO2 variations) during this time period may have affected the ability of subjects to complete a faster run bout. In addition, Bishop et al. (2002) have reported that the use of [La-] was one of the best variables to reflect the anaerobic contribution of exercise which may be more important during the VI ride. In the current study, no differences in VO2 (Table 1) and [La-] values were found at the end of cycling bouts, indicating no variations in aerobic and anaerobic demand between the three paced rides before running. These results were similar to those demonstrated by Liedl et al. (1999) showing similar [La-] and VO2 values at the end of constant versus variable-power effort during cycling. Thus, the improvement of running time after cycling at the $\mathrm{FCl}$ and $\mathrm{Cl}$ rides compared to the $\mathrm{VI}$ ride cannot be explained by the induced-metabolic responses during the cycling bouts.

Our findings reported during a C-R combination are in line with those of Palmer et al. (1997) showing an improved cycling performance after a prolonged constant- power session in cyclists, compared to a stochastic (variable) intensity bout. In these two studies, during the final 10 min of variable-intensity exercise, the subjects sustained high PO ( 300 to $350 \mathrm{~W})$ before subsequent exercise. Accordingly, the repeated increases in cycle intensity during the VI bout and especially during the last minutes of cycling may have resulted in muscular fatigue before running. Although no specific analysis of muscular parameters has been conducted in the current investigation, the change in neuromuscular activity of peripheral skeletal muscles remains an attractive hypothesis to explain the decrement in running performance after the VI ride. Selected lower extremity muscles such as rectus femoris, vastus lateralis, vastus medialis and soleus have been reported to be substantially recruited during cycling (Citterio and Agostini 1984; Marsh and Martin 1995; Takaishi et al. 1996) and running (Bijker et al. 2002; Borrani et al. 2001), suggesting that any changes in recruitment of these muscles during prior cycling may affect running performance.

During isolated cycling exercises, an increased activity of quadriceps and soleus muscles (from the EMG method) has been observed with increasing PO in a non-fatigued state (Citterio et Agostini 1984; Marsh and Martin 1995; Takaishi et al. 1996). One may speculate that during the repeated increases in power output experienced during the VI ride, there was a greater recruitment of these muscles, and associated changes in their contractile properties, resulting in an increased level of muscular fatigue during the subsequent run. Based on the same hypothesis, the lower activity of peripheral muscles after $\mathrm{FCl}$ and $\mathrm{Cl}$ rides might have reduced the fatigue level during cycling and improved their utilisation during the subsequent run, leading to higher running velocities from the first kilometer (Fig. 2). In this context, Duc et al. (2005) observed no change in muscular activity of four lower limb muscles (e.g. vastus medialis, rectus femoris) during a 30-min constant cycling exercise corresponding to the self-selected work 
intensity of subjects. The lack of increase in the EMG activity of muscles suggests that subjects performed the cycle-time-trial at a muscular work-steady state.

The hypothesis of peripheral neuromuscular changes is not exclusive to explain the differences in running performance between the conditions. The decrement in running performance after the stochastic cycling effort could also be determined by the central regulation of exercise performance based on the central governor model (Noakes et al. 2004; StClair Gibson and Noakes 2004). This theoretical model would predict that central recruitment of muscle function may be different depending on the nature of the prior exercise. Based on this model, we hypothesize that triathletes would decrease their level of muscle recruitment during the run consecutive to the cycle stochastic effort as compared to the constant cycle bout and hence, that might explain their impaired performance. In this theoretical context where the central command in the motor cortex is perceived as a sense of effort, the determinants of variable cycling exercise in our study might include the sense of effort and other sensations such as muscle pain which become more intense than is tolerable (StClair Gibson and Noakes 2004).

Furthermore, from running studies it has been reported that other neuromuscular factors may also be important determinants of endurance running performance (Nummela et al. 2006; Paavolainen et al. 1999). Paavolainen et al. (1999) have shown that a better performance in the $10 \mathrm{~km}$ time trial is related to higher pre-activation of the working muscles, associated with shorter contact times throughout the run. Recently, Nummela et al. (2006) reported that the impaired performance during a $5 \mathrm{~km}$ time trial is associated with a decreased pre-activation of lower limb muscles (from EMG measurements during the $100 \mathrm{~ms}$ before ground contact) and higher total ground contact times. Based on the interpretations of this recent study, we hypothesize that the fact to keep the level of muscular recruitment at a high level (i.e. high preactivation of lower limb muscles) contributes to the improved running performance in our triathletes when the prior cycling intensity remains constant.

Additional variables such as cycling cadence, have been reported to affect subsequent running performance (Bernard et al. 2003; Gottshall et Palmer 2002; Hausswirth et al. 2001; Vercruyssen et al. 2002, 2005). For instance, Gottshall and Palmer (2002) found that higher cycling cadence (>100 rpm), compared to the selection of lower cadences (70-90 rpm), immediately before running increased stride frequency and, as a result, increased running speed. These authors suggested that the combination of perseveration and central pattern generator effects may have contributed to the differences in running performance. In contrast, Vercruyssen et al. (2005) reported that the selection of low cycling cadence ( $75 \mathrm{rpm})$ compared to higher cadences (95-110 rpm) during the last $10 \mathrm{~min}$ of cycling markedly improved subsequent running time to fatigue. In contrast with previous authors (Sarre et al. 2005; Lepers et al. 2001) indicating that various cadences did alter in a similar extent the neuromuscular properties of knee extensors, the improved running performance after cycling at a low cadence in our study has been linked to the hypothesis of a lower muscular fatigue experienced during the last minutes of cycling. This improvement of running performance after the $\mathrm{Cl}$ ride, compared to the $\mathrm{FCl}$ bout, might be partially explained by the selection of a lower cadence during the last 3-km of cycling (Fig. 1) and its positive impact upon the delay of fatigue development. Because of the lack of specific analysis of muscular parameters during the pedalling and running tasks, the hypothesis of muscle recruitment and/or central recruitment of muscle function (e.g. Nummela et al. 2006) during the cycle-run combination performed at various cycling intensities needs to be validated in future research.

In conclusion, this study indicates that the selection of a constant PO during cycling improves subsequent running performance. Further research is necessary to analyse the relationship between neuromuscular activity and performance during a $\mathrm{C}-\mathrm{R}$ combination. From a practical standpoint, the best selected pacing cycling strategy in triathletes whatever the category of triathletes, would be to maintain a constant PO on a flat road, rather than a variable PO, for as long as possible before running. 


\section{Acknowledgments}

The authors gratefully acknowledge all the triathletes who took part in the experiment for their high cooperation and motivation.

\section{References}

Atkinson G, Davison R, Jeukendrup A, Passfield L (2003) Science and cycling: current knowledge and future directions for research. J Sports Sci 21:767-787

Bentley DJ, Millet GP, Vleck VE, MacNaughton LR (2002) Specific aspects of contempory triathlon. Sports Med 32:1- 15

Bernard T, Vercruyssen F, Grego F, Hausswirth C, Lepers R, Vallier JM, Brisswalter J (2003) Effect of cycling cadence on subsequent 3-km running performance in well-trained triathletes. Br J Sports Med 37:154-159

Bijker KE, De Groot G, Hollander AP (2002) Differences in leg muscle activity during running and cycling in humans. Eur J Appl Physiol 87:165-170

Bishop D, Bonetti D, Dawson B (2002) The influence of pacing strategy on _V O2 and supramaximal kayak performance. Med Sci Sports Exerc 34:1041-1047

Borg GA (1970) Perceived exertion as an indicator of somatic stress. Scand J Rehabil Med 2:92-98

Borrani F, Candau R, Millet GY, Perrey S, Fuchslocher J, Rouillon JD (2001) Is the _V O2 slow component dependent on progressive recruitment of fast-twitch fibers in trained runners? J Appl Physiol 90:2212-2220

Brandon LJ (1995) Physiological factors associated with middle distance running performance. Sports Med 95:268-277

Citerrio G, Agostini E (1984) Selective activation of quadriceps muscle fibers according to bicycling rate. J Appl Physiol 57:371-379

Duc S, Betik AC, Grappe F (2005) EMG activity does not change during a time trial in competitive cyclists. Int J Sports Med 26:145-150

Gottschall JS, Palmer BM (2002) The acute effects of prior cycling cadence on running performance and kinematics. Med Sci Sports Exerc 34:1518-1522 Hausswirth C, Lehenaff D, Dreano P, Savonen K (1999) Effects of cycling alone or in a sheltered position on subsequent running performance during a triathlon. Med Sci Sports Exerc 31:599-604

Hausswirth C, Vallier JM, Lehenafff D, Brisswalter J, Smith D, Millet G, Dreano P (2001) Effect of two drafting modalities in cycling on running performance. Med Sci Sports Exerc 33:385-390

Jones SM, Passfield L (1998) The dynamic calibration of bicycle power measuring cranks. In: Haake Sj (ed) The engineering of sport. Blackwell, Oxford, pp 265-274

Lepers R, Millet GY, Maffiuletti N (2001) Effect of cycling cadence on contractile and neural properties of knee extensors. Med Sci Sports Exerc 33:1882-1888

Lepers R, Maffiuletti N, Rochette L, Brugniaux J, Millet GY (2002) Neuromuscular fatigue during a long-duration cycling exercise. J Appl Physiol 92:1487-1493

Liedl MA, David PS, Branchi JD (1999) Physiological effects of constant versus variable power during endurance cycling. Med Sci Sports Exerc 31:1472-1477

MacLaughlin JE, King GA, Howley ET, Basset DR, Ainsworth Jr BE (2001) Validation of Cosmed K4b2 portable metabolic system. Int J Sports Med 22:280-284 
Marsh AP, Martin PE (1995) The relationship between cadence and lower extremity EMG in cyclists and noncyclists. Med Sci Sports Exerc 27:217-225

Noakes TD, St Clair Gibson A, Lambert EV (2004) From catastrophe to complexity: a novel model of integrative central neural regulation of effort and fatigue during exercise in humans: summary and conclusions. Br J Sports Med 39:120-124

Nummela AT, Paavolainen LM, Sharwood KA, Lambert MI, Noakes TD, Rusko HK (2006) Neuromuscular factors determining $5 \mathrm{~km}$ running performance and running economy in well-trained athletes. Eur J Appl Physiol 97:1-8

Paavolainen L, Nummela A, Rusko H, Hakkinen K (1999) Neuromuscular characteristics and fatigue during $10 \mathrm{~km}$ running. Int J Sports Med 20:516-521

Palmer GS, Noakes T, Hawley JA (1997) Effects of steady-state versus stochastic exercise on subsequent cycling performance. Med Sci Sport Exerc 29:684-687

Palmer GS, Borghouts LB, Noakes T, Hawley JA (1999) Metabolic and performance responses to constant-load vs. variable-intensity exercise in trained cyclists. J Appl Physiol 87:1186-1196

Perrey S, Candau R, Millet GY, Borrani F, Rouillon JD (2003) Physiological and metabolic responses of triathletes to a simulated 30 -min time-trial in cycling at self-selected intensity. Int J Sports Med 24:138-143

Pyne DB, Boston T, Martin DT, Logan A (2000) Evaluation of the lactate pro blood lactate analyser. Eur J Appl Physiol 82:112-116

Ramsay RL, Davies PD, Sharp NCC (2001) The effect of variable power output during cycling on subsequent run performance in triathletes. Med Sci Sports Exerc 33S:S341

Sarre G, Lepers R (2005) Neuromuscular function during prolonged pedalling exercise at different cadences. Acta Physiol Scand 185(4):321-328

StClair Gibson A, Noakes TD (2004) Evidence for complex system integration and dynamic neural regulation of skeletal muscle recruitment during exercise in humans. $\mathrm{Br} \mathrm{J}$ Sports Med 38:797-806

StClair Gibson A, Schabort EJ, Noakes TD (2001) Reduced neuromuscular activity and force generation during prolonged cycling. Am J Physiol Regul Integr Comp Physiol 281:R187R196

Swain DP (1997) A model for optimizing cycling performance by varying power on hills and in wind. Med Sci Sports Exerc 29:1104-1108

Takaishi T, Yamamoto T, Ono TY, Moritani T (1996) Optimal pedaling rate estimated from neuromuscular fatigue for cyclists. Med Sci Sports Exerc 28:1492-1497

Vercruyssen F, Brisswalter J, Hausswirth C, Bernard T, Bernard O, Vallier JM (2002) Influence of cycling cadence on subsequent running performance in triathletes. Med Sci Sports Exerc 34:530-536

Vercruyssen F, Suriano R, Bishop D, Hausswirth C, Brisswalter J (2005) Cadence selection affects metabolic responses during cycling and subsequent running time to fatigue. $\mathrm{Br} J$ Sports Med 39:267-272 

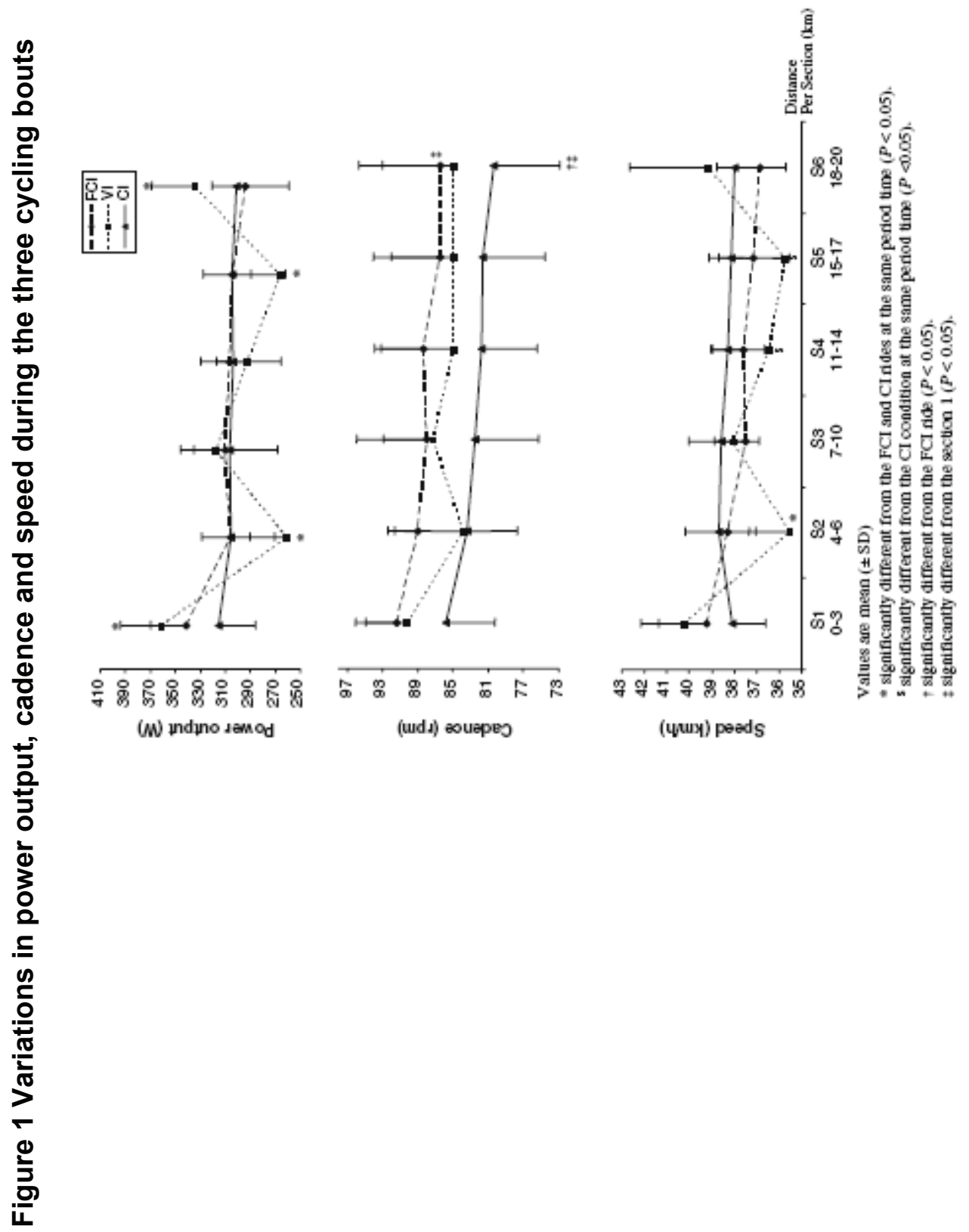


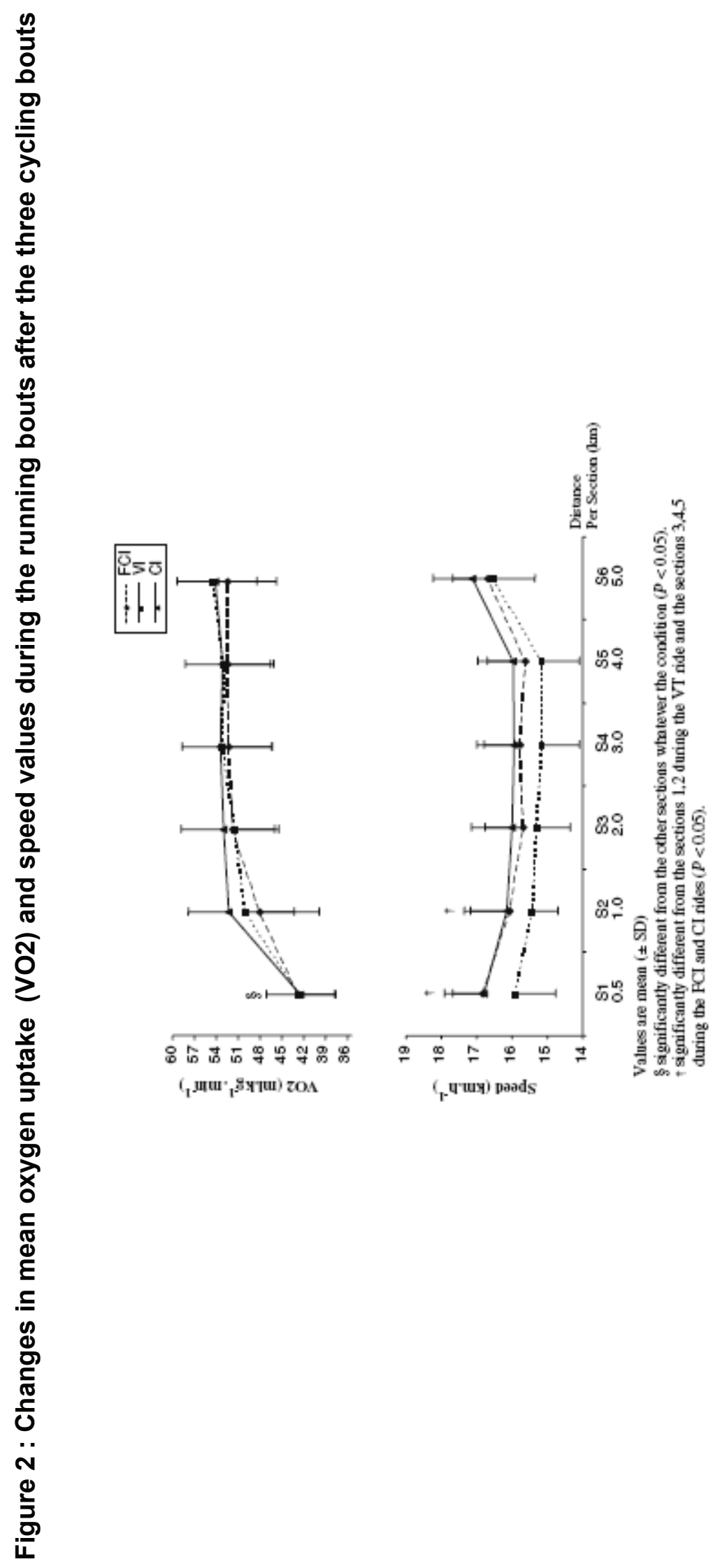



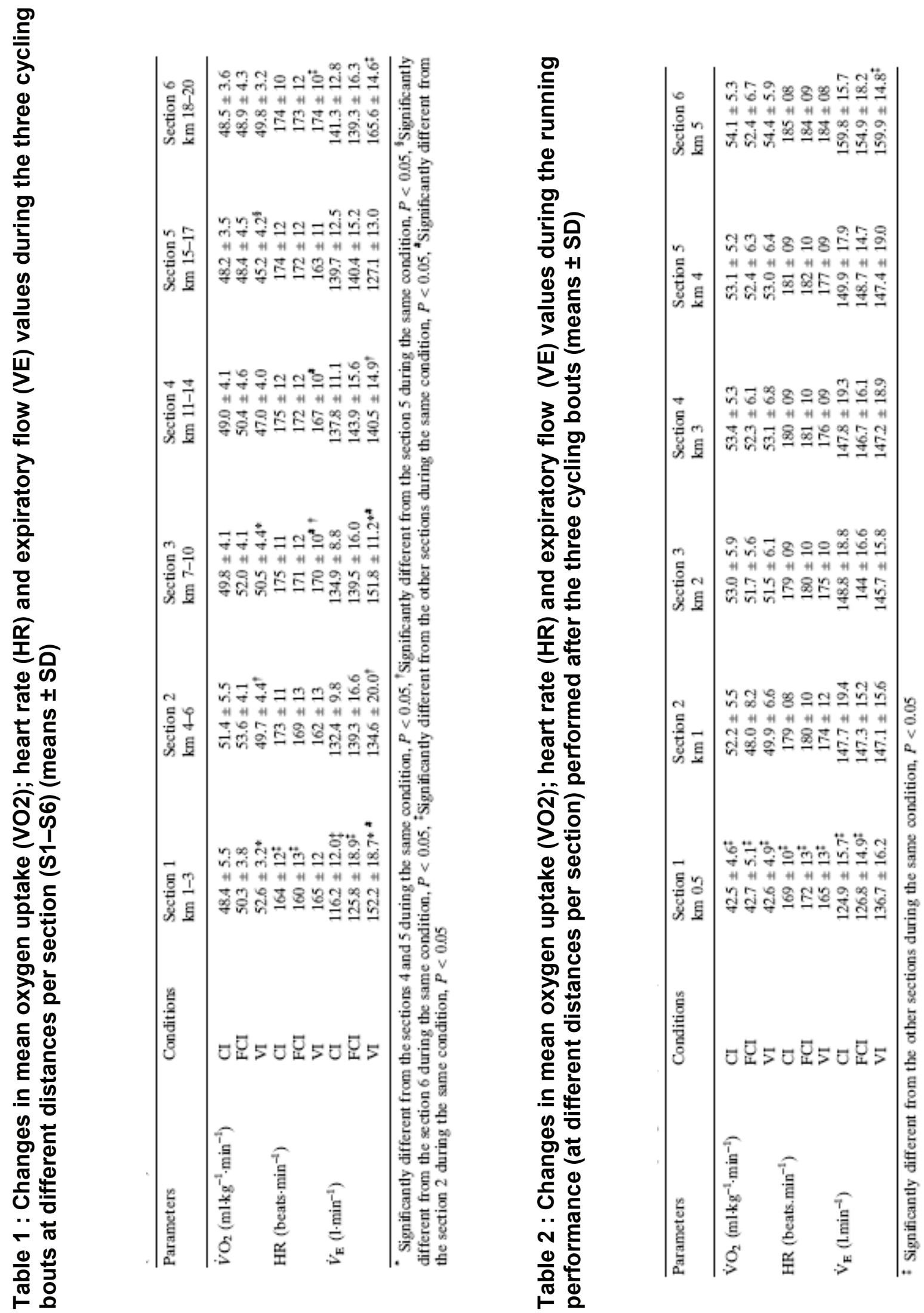